\title{
REVIEW ARTICLE \\ The epidemiology of meningococcal disease in Latin America 1945-2010: an unpredictable and changing landscape
}

\author{
M. A. P. SÁFADI ${ }^{1 *}$, S. GONZÁLEZ-AYALA ${ }^{2}$, A. JÄKEL ${ }^{3}$, H. WIEFFER ${ }^{3}$, \\ C. MORENO ${ }^{4}$ AND A. VYSE \\ ${ }^{1}$ Faculdade de Ciências Médicas da Santa Casa de São Paulo, São Paulo, Brazil \\ ${ }^{2}$ Hospital de Niños Superiora Sor Maria Ludovica, La Plata, Argentina \\ ${ }^{3}$ Heron Evidence Development Ltd, Luton, UK \\ ${ }^{4}$ GlaxoSmithKline Vaccines, Rio de Janeiro, Brazil \\ ${ }^{5}$ GlaxoSmithKline Vaccines, Wavre, Belgium
}

Received 23 January 2012; Final revision 11 May 2012; Accepted 11 July 2012; first published online 9 August 2012

\section{SUMMARY}

Meningococcal disease is mostly endemic in Latin America, with periodic occurrences of outbreaks and epidemics over the last few decades. This literature review summarizes the available epidemiological data for this region between 1945 and 2010. Incidence rates and serogroup distribution differ from country to country and over time. Serogroups A, B, and C have all been major causes of meningococcal disease since the 1970s. In the last decade serogroups W135 and Y may now be emerging in certain countries, with serogroup A virtually disappearing. Although progress has been made in improving and coordinating the surveillance of invasive disease, the uniformity and quality of reported data reflect the fact that the current surveillance systems focus on passive rather than active reporting, hence the reliability of data may vary between countries. Consideration of vaccination policies to control meningococcal disease can only be made with a sufficient understanding of the changing epidemiology in the region.

Key words: Epidemiology, Latin America, meningococcal disease, Neisseria meningitidis, vaccination strategies.

\section{INTRODUCTION}

Meningococcal disease (MD) is a serious, rapidly developing and potentially fatal infection. The causative agent, Neisseria meningitidis $(\mathrm{Nm})$, is commonly carried as part of the commensal microbiota in the upper respiratory tract of humans. However, occasionally the bacteria invade the bloodstream

\footnotetext{
* Author for correspondence: M. A. P. Sáfadi, M.D., Ph.D., Faculdade de Ciências Médicas da Santa Casa de São Paulo, Alameda dos Indigenas, 228, ZIP 04059-060. São Paulo, Brazil. (Email: masafadi@uol.com.br)
}

and cause serious invasive disease, manifesting as meningitis or septicaemia. For those patients who survive, a range of long-term sequelae may result from the infectious episode including hearing loss and amputation of limbs [1]. MD particularly affects children aged $<5$ years, especially infants. However, during outbreaks and epidemics, increased numbers of cases are often observed in adolescents and young adults [2].

Meningococci can be classified into different serogroups based on the antigenic properties of the polysaccharide capsule. To date, 13 serogroups of $\mathrm{Nm}$ have been identified, with serogroups A, B, C, W135, Y, 
and $\mathrm{X}$ accounting for virtually all cases of invasive disease [3, 4].

The epidemiology of MD is dynamic varying geographically both with time and serogroup. Most areas of the globe experience periods of endemic disease that are interrupted by hyperendemic periods and occasional epidemics [5]. Vaccination is considered the best control strategy for prevention of MD [6].

Epidemiological surveillance is particularly important for monitoring changes in incidence and serogroup distribution over time. Specifically in Latin America, the Pan American Health Organisation established the Sistema Regional de Vacunas (SIREVA) network in 1993, initially to monitor Streptococcus pneumoniae across the participating Latin American countries. This was extended to cover Haemophilus influenzae in 1997 and $\mathrm{Nm}$ was added in 2000; today, more than 20 countries in Latin America take part in this surveillance programme. However, the quality of (passive) surveillance and level of disease ascertainment varies by country across the region, with Brazil currently contributing the majority of data. The reliability of the data available for MD may therefore vary among countries in terms of completeness and accuracy.

Meningococcal polysaccharide-protein conjugate vaccines represent a major advance in MD prevention. Unlike plain polysaccharide vaccines, they can induce immunological memory providing an excellent boosting effect on re-exposure [7]. Meningococcal C conjugate vaccines have also been shown to prevent nasopharyngeal carriage and reduce transmission of $\mathrm{Nm}$ such that unvaccinated individuals are protected indirectly through a herd immunity effect $[8,9]$, which also increases the cost-effectiveness of vaccination programmes [10]. While evidence is only currently available for monovalent serogroup $\mathrm{C}$ conjugate vaccines, this is assumed to be a class effect that extends to other meningococcal conjugate vaccines that also use polysaccharide capsular antigens. However, the ability of new meningococcal vaccines to induce herd immunity that use alternative antigens will need to be demonstrated.

Due to the dynamic and unpredictable nature of the meningococcal epidemiology, combination conjugate vaccines against multiple meningococcal serogroups have been developed to broaden protection against the disease. The recent licensure of quadrivalent ACWY conjugate vaccines will build on current vaccine options to help achieve the most important goal of broad serogroup protection coverage [11].
However, the need for a broadly protective vaccine against serogroup B meningococci, a frequent cause of invasive MD in many parts of the world, remains important and is necessitating alternative approaches for vaccine development as the serogroup B capsular polysaccharide is poorly immunogenic $[12,13]$.

Historically, meningococcal vaccines have not been included in routine programs in Latin America, although mass vaccination campaigns have been implemented to control outbreaks and epidemics $[14,15]$. A notable exception is the routine infant vaccination programme that has been implemented in Cuba since the 1980s; this vaccination programme administers a vaccine comprising the serogroup $\mathrm{C}$ capsular polysaccharide and the outer membrane vesicles of serogroup B meningococcus [16]. Although this vaccine has been used elsewhere in Latin America (Colombia, Brazil, Uruguay, Argentina) for outbreak control [17-19], its potential for wider routine use is compromised by its limited serotype specificity for the serogroup B meningococcus and lack of evidence of protection in children aged $<2$ years [20]. However, in 2011 Brazil became the first country in the region to introduce a meningococcal $\mathrm{C}$ conjugate vaccine into the infant vaccination schedule, with two doses in the first year, at ages 3 and 5 months, and a booster dose at 12 months. Toddlers aged between 12 and 23 months receive one dose of the vaccine. At this moment no catch-up campaign for older age groups is planned [21].

This review assessed the extent of the available published epidemiological information for the Latin America region over the period 1945-2010, including examining information relating to epidemics and outbreaks, incidence and case-fatality rates (CFRs), carriage, serogroup distribution, and mortality and morbidity associated with MD, in order to describe the fluctuating nature of the disease both across the continent and through time.

\section{Searching and data availability}

Studies included in this review were identified through searches of the literature databases Medline, EMBASE, LILACS (Latin American and Caribbean Health Sciences), HISA (Latin American and Caribbean History of Public Health) and MEDCARIB (Caribbean Health Sciences Literature) from database start up to June 2010, combining search terms for Epidemiology AND Meningococcal Disease AND Latin America and the Caribbean in Spanish, Portuguese and English for the period 
1945-2010. A detailed search strategy is provided in online Supplementary Table S1. The reference lists of relevant articles were used to identify further citations of interest. Additional searches were conducted of the websites of national and international public health agencies. English, Spanish and Portuguese language publications were included.

Abstracts from literature databases, subsequently sourced full publications and information on websites were evaluated for inclusion if the source provided information on the incidence of disease, occurrence of outbreaks/epidemics or mortality rates for MD in Latin American and Caribbean countries for period 1945-2010. Information from these studies was extracted relevant to each component of the study objective and described in a qualitative manner.

The searches conducted indicate that there is a lack of more historical data available in the published literature for some countries. Despite intensive searching there were no incidence data available on invasive MD in several countries in the region. This lack of data is likely to reflect the lack of a formal surveillance system to chart epidemics in these countries and also the presence of endemic disease. In contrast, the monitoring of and research into MD is well-developed in other countries, including Brazil, Uruguay, Argentina, Chile, Colombia and Cuba, leading to more extensive data availability for these countries. Therefore, while MD surveillance is improving in the region, caution is needed when interpreting data from those countries where there are less well-developed surveillance systems and available data may be more limited [22].

\section{Epidemic and endemic disease and the changing serogroup distribution, 1970-2010}

Very limited data on the epidemiology of MD in Latin America were available prior to the 1970s (Table 1). Data for Mexico and Brazil associated with epidemics were identified for the late 1940s, with about 753 registered cases in Mexico seen for the period 1945-1949 [23] and a serogroup A epidemic from 1945 to 1951 in Sao Paulo, Brazil with incidence rates of 4.6-24.2 cases/100 000 inhabitants [24, 25]. Due to scarcity of more historical data, the following sections focus on the epidemiology from 1970 onwards.

In comparison with those countries experiencing high incidence and epidemics during the past 40 years, some countries in Latin America have only experienced low-level endemic rates of MD. Notably, Mexico has remained relatively unaffected since the
1940 s and reports very low incidence of disease $[23,26]$. SINAVE (Sistema Nacional de Vigilancia Epidemiológica) registered an average of 65 confirmed cases per year between 2003 and 2009 and, based on a total of 60 reported cases in 2006, a national incidence of 0.056 cases $/ 100000$ has been estimated. However, a recent hospital-based active surveillance study performed on the border of Mexico and the USA suggested that the incidence in this region and in the rest of Mexico may be substantially higher than previously reported, with 3.08 and 0.69 cases $/ 100000$ children aged $<17$ years estimated during 2005-2008 in Tijuana and San Diego, respectively [27].

While the current incidence of endemic MD in Latin America is typically $<2$ cases/ 100000 population per year [21], epidemic disease has broken out in all parts of Latin America at different times during the past 40 years. The reported epidemics and outbreak clusters identified in the literature are displayed in Figure 1. Of Latin America as a whole, Brazil has reported the most outbreaks and epidemics, although this may be partly attributed to the existence of a well-established surveillance system. The available data highlight the occurrence of MD epidemics in Latin America associated with different serogroups and reflect the unpredictable nature of MD epidemiology.

\section{Serogroup A}

Although serogroup A is now extremely rare on the continent [28], serogroup A epidemics with high incidence rates were reported in the 1970s [24, 25]. In 1974 , the spread of a serogroup A epidemic strain during an existing serogroup $\mathrm{C}$ epidemic period in Sao Paulo, Brazil resulted in incidence estimates as high as 180 cases/100 000 population per year [24, 25]. This epidemic provided the first major experience with polysaccharide $\mathrm{A}$ and $\mathrm{C}$ vaccines on a large scale, resulting in the successful control of the epidemic [25]. Serogroup A was also the dominant serogroup in an MD outbreak in southern Chile in 1978/1979 with an incidence estimate of 21 cases/100 000 population per year $[14,29]$. Following vaccination with polysaccharide $\mathrm{A}$ and $\mathrm{C}$ vaccine, $\mathrm{MD}$ incidence levels in Chile reverted to background levels of $0 \cdot 8-1 \cdot 1$ cases/ 100000 population per year [14].

\section{Serogroup B}

Serogroup B epidemics were reported in several Latin American countries in the 1980 s, associated with the international spread of epidemic clones of the 
Table 1. Incidence and case-fatality rates of meningococcal disease, with serogroup specific information, if available, in several countries in Latin America (arranged by country and year)

\begin{tabular}{|c|c|c|c|c|c|}
\hline Ref. & Region & $\begin{array}{l}\text { Year of } \\
\text { observation }\end{array}$ & Incidence & CFR & Serogroup information \\
\hline \multicolumn{6}{|c|}{ Mexico } \\
\hline$[67]$ & Mexico & 1993-2003 & Low incidence & NR & NR \\
\hline [68] & Mexico & 1990-2004 & 0-78 cases/year & NR & NR \\
\hline \multirow[t]{2}{*}{ [26] } & Mexico & 1990-2002 & $0-73$ cases $/$ year & NR & NR \\
\hline & & 2003-2008 & $52-82$ cases/year & NR & NR \\
\hline \multicolumn{6}{|c|}{ Cuba } \\
\hline [69] & Cuba & & $0 \cdot 3-0 \cdot 7 / 100000$ & $0-10 \cdot 5 \%$ & NR \\
\hline \multirow[t]{2}{*}{ [32] } & Cuba & 1983 & $14 \cdot 4 / 100000$ & NR & $100 \% \mathrm{~B}$ \\
\hline & & 1992 & $1 \cdot 4 / 100000$ & & \\
\hline \multicolumn{6}{|c|}{ Panama } \\
\hline \multirow[t]{2}{*}[70]{} & Panama & 1990 & $4 \cdot 6 / 100000$ & NR & NR \\
\hline & & 2008 & $1 / 100000$ & NR & NR \\
\hline \multicolumn{6}{|c|}{ Costa Rica } \\
\hline$[45]$ & Costa Rica & $1970-1973$ & $2 \cdot 4-7 \cdot 8 / 100000$ & $11-18 \%$ & NR \\
\hline \multicolumn{6}{|c|}{ Brazil } \\
\hline \multicolumn{6}{|c|}{ North } \\
\hline$[71]$ & $\begin{array}{l}\text { Manaus, } \\
\text { Amazonas }\end{array}$ & 1998-2002 & $7 \cdot 8 / 100000$ & $14 \%$ & 2002: $78 \cdot 2 \% \mathrm{~B}, 7 \cdot 2 \% \mathrm{C}$ \\
\hline \multicolumn{6}{|c|}{ North-East } \\
\hline [72] & Salvador (Bahia) & 1996-2001 & $1 \cdot 24-2 \cdot 23 / 100000$ & $8 \%$ & $82 \% \mathrm{~B}, 16 \% \mathrm{C}, 2 \% \mathrm{~W} 135,0.3 \% \mathrm{Y}$ \\
\hline \multicolumn{6}{|c|}{ South } \\
\hline [73] & Rio Grande do Sul & 1995-2003 & $1 \cdot 8-3 \cdot 5 / 100000$ & $17 \%$ & $\begin{array}{l}79 \% \mathrm{~B}, 14 \cdot 1 \% \mathrm{C}, 6 \cdot 2 \% \mathrm{~W} 135 \text {, } \\
0 \cdot 7 \% \text { Other }\end{array}$ \\
\hline$[55]$ & Rio Grande do Sul & 2003-2005 & $1 \cdot 54 / 100000$ & NR & $64 \% \mathrm{~B}, 18 \% \mathrm{C}, 17 \% \mathrm{~W} 135,1 \% \mathrm{Y}$ \\
\hline [74] & Santa Catarina & 1988-1991 & $1 \cdot 8-5 \cdot 4 / 100000$ & $19 \cdot 6 \%$ & 1989-1990 B epidemic \\
\hline \multirow[t]{3}{*}[15]{} & Santa Catarina & $\begin{array}{l}1971-1975 \\
\quad \text { (epidemic) }\end{array}$ & $9 \cdot 6 / 100000$ & $21 \cdot 1 \%$ & NR \\
\hline & & $\begin{array}{r}1976-1985 \\
\text { (endemic) }\end{array}$ & $3 \cdot 2 / 100000$ & $20 \cdot 6 \%$ & $\begin{array}{l}\text { 1981-1985: B } 83.9 \%, \text { C } 2 \cdot 1 \% \text {, } \\
\text { Other } 14 \%\end{array}$ \\
\hline & & $\begin{array}{l}1986-2000 \\
\quad(\text { epidemic) }\end{array}$ & $7 \cdot 4 / 100000$ & $15 \cdot 2 \%$ & B $69 \cdot 1 \%$, C $27 \cdot 7 \%$, Other $3 \cdot 2 \%$ \\
\hline \multirow[t]{3}{*}{ [47] } & Curitiba & 1989 & $2 \cdot 14 / 100000$ & NR & B $70.6 \%$, C $23.5 \%$, Other $5.9 \%$ \\
\hline & Parana & 1990 & $10 \cdot 45 / 100000$ & & $\begin{array}{l}\text { Epidemic of B } 17 \cdot 9 \%, \mathrm{C} 82 \cdot 1 \% \text {, } \\
\text { Other } 0 \%\end{array}$ \\
\hline & & 1991 & $6 \cdot 5 / 100000$ & NR & B $29 \cdot 3 \%$, C $70 \cdot 7 \%$, Other $0 \%$ \\
\hline \multicolumn{6}{|c|}{ South-East } \\
\hline \multirow[t]{3}{*}{ [33] } & Sao Paulo & 1977 & $3 \cdot 3 / 100000$ & NR & NR \\
\hline & & 1982 & $1 \cdot 05 / 100000$ & NR & NR \\
\hline & & 1990 & $5 \cdot 4 / 100000$ & NR & NR \\
\hline$[46]$ & Sao Paulo & & Overall $11 \cdot 3 / 100000$ & $9 \cdot 2 \%$ & \\
\hline \multirow[t]{4}{*}{ [25] } & Sao Paulo & $\begin{array}{l}1920-26 \\
\text { (epidemic) }\end{array}$ & $4 \cdot 7-12 \cdot 2 / 100000$ & NR & NR \\
\hline & & $\begin{array}{l}1945-51 \\
\quad(\text { epidemic) }\end{array}$ & $4 \cdot 6-24 \cdot 2 / 100000$ & NR & NR \\
\hline & & $\begin{array}{l}1971-76 \\
\text { (epidemic) }\end{array}$ & $5 \cdot 9-180 / 100000$ & NR & NR \\
\hline & & $\begin{array}{l}1988-2000 \\
\quad(\text { epidemic) }\end{array}$ & $4 \cdot 4-8 \cdot 25 / 100000$ & NR & NR \\
\hline \multirow[t]{3}{*}[75]{} & Sao Paulo & 1958-19676 & NR & $19 \cdot 1 \%$ & NR \\
\hline & & 1968-1972 & & $13 \cdot 7 \%$ & NR \\
\hline & & $\begin{array}{l}1958-1972 \\
\text { (total) }\end{array}$ & & $15 \cdot 3 \%$ & NR \\
\hline
\end{tabular}


Table 1 (cont.)

\begin{tabular}{|c|c|c|c|c|c|}
\hline Ref. & Region & $\begin{array}{l}\text { Year of } \\
\text { observation }\end{array}$ & Incidence & CFR & Serogroup information \\
\hline [76] & $\begin{array}{l}\text { Campinas } \\
\text { Sao Paulo }\end{array}$ & 1993-1998 & NR & $17 \cdot 3 \%$ & \\
\hline \multirow[t]{3}{*}{ [77] } & Rio de Janeiro & $\begin{array}{l}\text { 1976-1979 } \\
\text { (post- } \\
\text { epidemic) }\end{array}$ & $3 \cdot 51 / 100000$ & $18 \cdot 4 \%$ & A $63.4 \%$, B $4.9 \%$, C $31.7 \%$ \\
\hline & & $\begin{array}{l}\text { 1980-1986 } \\
\text { (Endemic) }\end{array}$ & $1 \cdot 67 / 100000$ & $16 \cdot 2 \%$ & A $38.3 \%$, B $44.4 \%$, , $17.3 \%$ \\
\hline & & $\begin{array}{l}\text { 1987-1994 } \\
\text { (Epidemic) }\end{array}$ & $6 \cdot 53 / 100000$ & $16 \cdot 4 \%$ & A $1 \cdot 1 \%$, B $80 \cdot 1 \%$, C $18 \cdot 8 \%$ \\
\hline [50] & Whole country & $2000-2010$ & $2 \cdot 52-1 \cdot 36 / 100000$ & $20 \%$ & NR \\
\hline \multicolumn{6}{|c|}{ Colombia } \\
\hline & Colombia & 1995-1998 & $0 \cdot 6-0 \cdot 8 / 100000$ & NR & NR \\
\hline \multicolumn{6}{|c|}{ Uruguay } \\
\hline \multirow[t]{6}{*}{ [19] } & Canelones & $2000-2001$ & $1 \cdot 5 / 1000000$ & $\begin{array}{l}27 \% \\
\text { (epidemic) }\end{array}$ & NR \\
\hline & & 2001-2002 & $3 \cdot 4 / 100000$ & NR & NR \\
\hline & & $\begin{array}{l}\text { After } \\
\text { vaccination }\end{array}$ & $1 \cdot 8 / 100000$ & $12 \cdot 5 \%$ & NR \\
\hline & Montevideo & $2000-2001$ & $1 \cdot 5 / 1000000$ & $5 \%$ & NR \\
\hline & & 2001-2002 & $2 \cdot 3 / 100000$ & $10 \%$ & NR \\
\hline & & $\begin{array}{l}\text { After } \\
\text { vaccination }\end{array}$ & $1 \cdot 8 / 100000$ & $4 \cdot 5 \%$ & NR \\
\hline \multicolumn{6}{|c|}{ Argentina } \\
\hline [79] & Argentina & 1990-2003 & $0 \cdot 6-2 \cdot 9 / 100000$ & NR & NR \\
\hline [80] & Argentina & (not specified) & $0 \cdot 7 / 100000$ & NR & NR \\
\hline \multicolumn{6}{|l|}{ Chile } \\
\hline [14] & Iquique & $1979-1987$ & $\begin{array}{l}\text { Attack rate }>20 / \\
100000 / \text { year during } \\
\text { serogroup B } \\
\text { outbreak }\end{array}$ & $5 \cdot 7 \%$ & NR \\
\hline [81] & Santiago & 1994 & $\begin{array}{l}\text { 1993: 5.9/100 } 000 \\
\text { (epidemic) }\end{array}$ & NR & NR \\
\hline [58] & Chile & 2009 & $0 \cdot 6 / 100000$ & $8.9 \%$ & NR \\
\hline
\end{tabular}

CFR, Case-fatality rate; NR, not recorded.

ET5/ST32 type previously responsible for outbreaks in Europe and the USA [30]. This clone was associated with epidemic disease in Cuba, with a peak incidence of 14 cases/100000 reported in 1983 [31]. The most prevalent strain in this outbreak was $\mathrm{B}: 4: \mathrm{P} 1.19,15: \mathrm{L} 3,7,9$, belonging to the ET5 type [32]. This strain was also important in epidemics in Brazil in the late 1980s [33, 34], and was identified as dominant in Brazil in the 1990s [35]. An outbreak of serogroup B MD in Iquique, Chile, progressed rapidly in the early 1980s and reached incidence rates of over 20/100 000 population per year [14]. The outbreak was attributed to the $\mathrm{B}: 15: \mathrm{P} 1.3$ strain, which belongs to the same genetic clone of the ET5 type as the Cuban strain [14].
The Cuban B (outer membrane vesicles)/C (polysaccharide) vaccine was developed in response to the serogroup B epidemic in 1983 (based on the prevalent serotype at that time in Cuba) and was used in a mass vaccination programme during 1987-1989 [36]. This was associated with a decreased incidence of MD [36] and, in 1991, the vaccine was incorporated into the Cuban routine national immunization programme. This vaccine was also used in other Latin American countries in subsequent years in response to serogroup B epidemics, such as in Brazil [18, 37], Uruguay [19], and Colombia [38]. However, various studies estimating the effectiveness of the Cuban $\mathrm{B} / \mathrm{C}$ vaccine suggest that it does not provide protection against heterologous strains, and only 


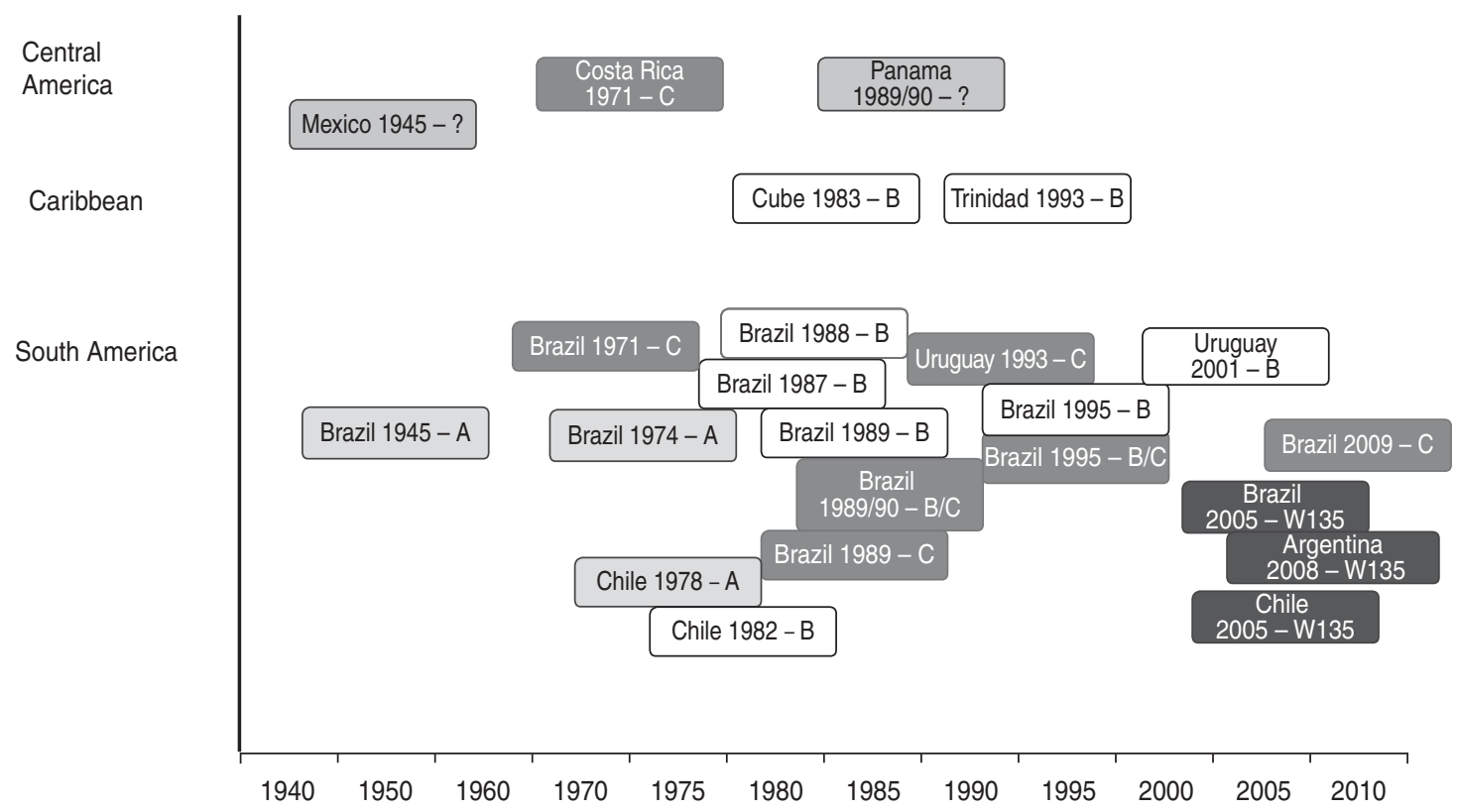

Fig. 1. Chronological overview of epidemics and outbreaks in Latin America by serogroup. Serogroups associated with each epidemic or outbreak are listed alongside the year of the event and the country. The occurrence of serogroup A is shown in light grey, serogroup C in dark grey, serogroup B is highlighted in white, and serogroup W135 in black.

provides modest protection in young children [17-20, 37].

Before the introduction of the SIREVA network in 2000, limited information on endemic serogroup prevalence was identified from the published literature. Those studies that are available indicate that serogroup B was the most prevalent endemic disease serogroup pre-2000 in several countries in Latin America, including Colombia ( $78 \%$ of isolates identified between 1994 and 2006) [39], Chile (over $90 \%$ of isolates identified between 1992 and 1993) [40], Brazil [21] and Uruguay [19, 41]. However, although the incidence of $\mathrm{MD}$ in Cuba after the introduction of vaccination remained at $<1.4$ cases $/ 100000$ population per year from 1992 onwards, a sample of 111 isolates tested from subsequent years indicated that serogroup B, particularly the B:4:P1.15 serotype, remained the dominant cause of disease [32].

Since the inclusion of $\mathrm{Nm}$ in the SIREVA surveillance network in 2000, information on the number of serogroup isolates across Latin America has been more readily available, although caveats of reliability apply. Since then, serogroup B has been common in Cuba, Chile, Argentina and Uruguay [28, 42-44].

\section{Serogroup C}

Outbreaks of serogroup C MD were reported in the 1970s in Costa Rica, with an incidence of
$2 \cdot 4$ cases/ 100000 population per year reported in 1970 increasing to 7.8 cases $/ 100000$ population per year in 1971/1972 [45]. However the majority of serogroup C outbreaks and epidemics have been reported in Brazil $[15,46,47]$. Molecular analyses have identified two major serogroup $\mathrm{C}$ clones circulating in greater Sao Paulo, Brazil, that were associated with these MD outbreaks during the period 1976-2000 [48]. Initially, the ST11 complex (serotype 2a strain) was identified in 1976 and may have been responsible for a serogroup C epidemic in the early 1970s. This was replaced by the ET11 complex (serotype 2b strain) in $1989 / 1990$, which may have subsequently been responsible for epidemic disease [47, 49]. Outbreaks of serogroup $\mathrm{C}$ disease were identified in Curitiba, the capital of Parana state in Brazil, that reached a peak incidence of 10 cases/100 000 population in 1990 [47]. Further serogroup $\mathrm{C}$ epidemics were reported in Rio de Janeiro during 1993-1995 [49] and from 2002 onwards a significant increase in the proportion of cases attributed to serogroup C (ST103 complex) was observed. Currently, serogroup $\mathrm{C}$ is the most frequently observed serogroup causing MD in Brazil [21]. Most recently, several outbreaks of MD caused by serogroup $\mathrm{C}$ that affected various cities in Brazil were registered [21].

As a consequence of the current epidemiological situation and also of ongoing serogroup $\mathrm{C}$ outbreaks in Brazil, the meningococcal serogroup $\mathrm{C}$ conjugate 
vaccine was introduced into the routine infant vaccine schedule in Brazil in late 2010 [50].

Serogroup $\mathrm{C}$ has also been an important contributor to endemic disease, particularly during the late 1990s and early 2000s. For example, Argentina saw an increase in serogroup C disease in the 1990s, overtaking serogroup B during the period 1995-2001 [21, 51]. Similarly, serogroup $C$ was an important contributor to disease in Sao Paulo, Brazil, during the period 1990-2002 [48]. Since 2000, Colombia and Brazil have reported increases in serogroup $\mathrm{C}$ disease [44].

\section{Serogroup W135}

Before 2000, disease caused by serogroup W135 was rarely observed in Latin America. However, there is now evidence to suggest that serogroup W135 may have emerged in Argentina and Chile, with the prevalence of this serogroup increasing from no cases in 2001 to $31 \%$ of total cases by November 2011 [52] within Chile and from $2 \%$ of cases with confirmed serogroup in 2000 to $37 \%$ in 2008 and $47 \%$ in 2009 within Argentina [28, 44, 53]. Clusters of MD cases resulting from serogroup W135 have also been reported in Brazil [54, 55]. The emergence of serogroup W135 in Latin America has been linked to the hypervirulent Hajj clone W135:P1.5,2:ST11 (ST11/ET37 clonal complex), which emerged in 2000 and has since spread internationally [54, 55]. In addition to outbreaks and epidemics, this Hajj clone has also been associated with high CFRs in South Africa [56].

\section{Serogroup $Y$}

Serogroup Y emerged in North America in the mid1990s and now causes about one third of all MD occurring in the USA [7]. Prior to the 21st century serogroup Y disease was seldom observed in Latin America. However, since 2003, serogroup Y MD has been increasingly reported in Colombia, possibly accounting for half of all those cases confirmed in 2006 [39]. Similarly, a slight increase in the incidence of serogroup Y MD has also been reported recently in Venezuela, Argentina, Costa Rica, Chile, and Uruguay [28, 42-44]. Molecular characterization of isolates has identified that the serogroup $\mathrm{Y}$ isolates found in Colombia and Costa Rica are similar to those prevalent in the USA, suggesting spread within the wider American continent, with the majority belonging to the ST23 clonal complex [57]. In contrast, the isolates found in Argentina relate predominantly to a different clonal complex, indicating that these strains may have been introduced by other routes.

\section{Case fatality}

CFRs between $10 \%$ and $20 \%$ have been reported in recent years in several countries within Latin America, including Chile $(14 \%$ in 2010) [58], Argentina $(7 \%-15 \%)$ [59], Panama (12.5\%) [60], Mexico (18\% in 2005-2008) [27] and Uruguay (15\%) [61]. Furthermore, a notably high case fatality $(\sim 20 \%)$ continues to be reported in Brazil despite the increasing availability of intensive-care units and improvements in healthcare. During the recent outbreaks in Brazil that have mostly been associated with serogroup $\mathrm{C}$, particularly high case fatality risks of about $40 \%$ have been reported [62]. In general the CFR for MD is considered to be on average $\sim 10 \%$ (with no consistent difference observed by global region) which is somewhat lower in comparison to those data currently available for Latin America. Possible reasons for these high CFR, particularly in Brazil, remain speculative and could be related to lack of timely access to healthcare facilities in determined regions of the country. Furthermore, since 2002 Brazil has reported a significant increase in the number and proportion of cases attributed to serogroup $\mathrm{C}$ that is associated with a new clonal complex, ST103, which is not commonly observed globally at present [48]. Emergence of new virulent clones might be associated with high incidence rates and increased CFRs among susceptible populations.

\section{Carriage}

Very limited published data describing carriage of $\mathrm{Nm}$ in Latin America are currently available. Of the published data identified, information relating to carriage is limited to children and adolescents from small populations residing within limited geographical areas [63, 64]. A carriage prevalence of $1.9 \%$ in children and $2.9 \%$ in adolescents was reported in Mexico [64], with $\mathrm{Nm}$ serogroups $\mathrm{C}$ and $\mathrm{Y}$ being the most frequently detected. Similarly, carriage of $\mathrm{Nm}$ was found to be $1.5 \%$ in a sample of schoolchildren in Venezuela [63].

Understanding carriage of the meningococcus represents a major knowledge gap both regionally within Latin America and globally, with various key issues requiring further investigation that are also 
currently hampered by a lack of standard methodology [65]. However, while existing data mainly generated in European populations [65] are considered limited and are now becoming historical, a key conclusion is that age appears to be a key determinant of meningococcal carriage prevalence, often peaking in adolescents and young adults, and is important for understanding the epidemiology and transmission dynamics of meningococcal infection [66]. Further carriage studies in Latin America to investigate carriage prevalence by age may therefore be valuable to confirm those key age groups in the region involved in transmission and also assess the extent to which existing data are relevant to Latin American populations. The availability of regionally representative carriage data will also be useful for assessing more precisely the extent and potential that exists for inducing herd immunity in Latin American populations. This will help informed decisions to be made should vaccination strategies need to be considered within the region that optimize the herd protection that not only those currently available meningococcal conjugate vaccines are able to provide but also for new meningococcal vaccines that may become available that have potential to induce herd protection.

\section{CONCLUSIONS}

This review highlights the dynamic and unpredictable nature of MD epidemiology over time (1945 to present) and between the countries within this region. There were important limitations in the availability of published data for some countries, particularly for earlier time periods, which limit the conclusions that can be drawn on the changing epidemiology of MD in Latin America over time.

Although progress has been made in improving and coordinating the surveillance of invasive disease with the implementation of a laboratory surveillance network (SIREVA), under-reporting may be prevalent and the amount of information is variable across Latin America. The low rates of MD and the high proportion of meningitis without an identified bacterial cause reported by several countries reflect the lack of access to hospital care and the limitations in obtaining adequate samples for culture in most of the region. This results in underestimation of the real burden and may impact the understanding of the serogroup distribution of MD in Latin America.

As well as differences in reporting due to variation in access to hospitals and laboratories, it is also possible that different case definitions may be used for MD in Latin American countries, making comparisons across the region unreliable. A standardized case definition combining WHO criteria with confirmatory laboratory diagnosis, e.g. by real-time PCR is needed to provide accurate estimates of the true burden of MD in the region.

Evidence suggests that serogroup A disease has virtually disappeared from Latin America. Serogroups B and $\mathrm{C}$ are currently responsible for the majority of cases reported in the region. A significant rise in the proportion of cases due to serogroup C, associated with the ST103 complex, occurred recently in Brazil, where it currently represents $80 \%$ of cases, while in Chile, Uruguay and in most countries from Central America and the Caribbean the majority of cases are due to serogroup B. There is recent evidence of the emergence of serogroup W135, associated with the ST11 complex, in Argentina, especially in the province of Buenos Aires, and it has also been observed in regions of Brazil and Chile. Additionally, serogroup $\mathrm{Y}$ has been observed in Colombia, where in 2006 it represented almost $50 \%$ of the isolates identified. Venezuela has also recently reported an increase in the proportion of cases due to serogroup Y. However, various countries may substantially underreport the annual number of cases, suggesting current estimates of serogroup distribution should be viewed with some caution.

The lack of carriage data in the Latin American region represents a major knowledge gap. There may be a role for wider contemporary carriage studies within the region to help further understand the epidemiology and identify key transmission groups so that vaccine strategies can be considered that maximize potential herd protection that can be obtained using meningococcal conjugate vaccines.

Historically, plain polysaccharide vaccines have been used in Latin America to control MD outbreaks and epidemics and were not included as part of universal routine vaccination programmes. Exceptions where routine vaccination was adopted include Cuba and more recently Brazil, which became the first country in the region to introduce meningococcal serogroup $\mathrm{C}$ conjugate vaccine into its routine schedule. With the emergence of the previously rare serogroups W135 and Y, against which susceptibility of the population is expected, and the now wider availability of quadrivalent A, C, W135 and Y polysaccharide-protein conjugate vaccines, the potential to consider strategies that provide broader protection 
and maximize potential herd protection exists. The currently investigational recombinant protein vaccines against serogroup B disease are likely to become available in the next years, broadening the possibility of protection against the disease.

In conclusion, Neisseria meningitidis remains an important cause of disease in Latin America with evidence suggesting a dynamic epidemiology. Informed decisions for appropriate vaccination strategies to control MD can only be made with a sufficient understanding of the changing epidemiology in the region and the availability of appropriate data. Therefore, there is a need to improve and establish more uniform quality surveillance across the region.

\section{SUPPLEMENTARY MATERIAL}

For supplementary material accompanying this paper visit http://dx.doi.org/10·1017/S0950268812001689.

\section{ACKNOWLEDGEMENTS}

GlaxoSmithKline Biologicals paid for all costs associated with the literature research, writing and publication assistance of this manuscript. The authors thank Wouter Houthoofd (XPE Pharma and Science, on behalf of GlaxoSmithKline Biologicals) for editorial assistance in coordination and submission of the manuscript.

\section{DECLARATION OF INTEREST}

M.S. has received consultation and lecture fees from Baxter, GlaxoSmithKline, MSD, Novartis, SanofiPasteur and Wyeth. S.A. has received consultation fees from GlaxoSmithKline, payment for expert testimony from Sanofi-Pasteur and Novartis, and for development of educational presentations from Pfizer. A.J. and H.W. are employees of Heron Evidence Development Ltd which received funding from GlaxoSmithKline Biologicals to conduct research for this study and to provide writing assistance for this manuscript. C.M. and A.V. are employees of GlaxoSmithKline Biologicals, which has a quadrivalent meningococcal conjugate vaccine approved by EMA in April 2012.

\section{REFERENCES}

1. Edmond K, et al. Global and regional risk of disabling sequelae from bacterial meningitis: a systematic review and meta-analysis. Lancet Infectious Diseases 2010; 10: 317-328.

2. Peltola H, Kataja JM, Makela PH. Shift in the agedistribution of meningococcal disease as predictor of an epidemic? Lancet 1982; 2: 595-597.

3. Boisier $\mathbf{P}$, et al. Meningococcal meningitis: unprecedented incidence of serogroup X-related cases in 2006 in Niger. Clinical Infectious Diseases 2007; 44: $657-663$.

4. Leimkugel J, Racloz V. Global review of meningococcal disease. A shifting etiology. Journal of Bacteriology Research 2009; 1: 6-18.

5. Harrison LH, Trotter CL, Ramsay ME. Global epidemiology of meningococcal disease. Vaccine 2009; 27 (Suppl. 2): B51-B63.

6. Center for Disease Control and Prevention. Revised recommendations of the Advisory Committee on Immunization Practices to vaccinate all persons aged 11-18 years with meningococcal conjugate vaccine. Morbidity and Mortality Weekly Report 2007; 56: 794-795.

7. Granoff DM, Pollard AJ. Reconsideration of the use of meningococcal polysaccharide vaccine. Pediatric Infectious Disease Journal 2007; 26: 716722.

8. Maiden MC, et al. Impact of meningococcal serogroup C conjugate vaccines on carriage and herd immunity. Journal of Infectious Diseases 2008; 197: 737-743.

9. Trotter CL, Maiden MC. Meningococcal vaccines and herd immunity: lessons learned from serogroup C conjugate vaccination programs. Expert Review of Vaccines 2009; 8: 851-861.

10. Trotter CL, Edmunds WJ. Reassessing the cost-effectiveness of meningococcal serogroup $\mathrm{C}$ conjugate (MCC) vaccines using a transmission dynamic model. BMC Medical Informatics and Decision Making 2006; 26: 38-47.

11. Pace D. Quadrivalent meningococcal ACYW-135 glycoconjugate vaccine for broader protection from infancy. Expert Review of Vaccines 2009; 8: 529-542.

12. Finne J, Leinonen M, Makela PH. Antigenic similarities between brain components and bacteria causing meningitis. Implications for vaccine development and pathogenesis. Lancet $1983 ; 2$ : 355-357.

13. Tan LKK, Carlone GM, Borrow R. Advances in the development of vaccines against Neisseria meningitidis. New England Journal of Medicine 2010; 362: 15111520.

14. Cruz C, et al. Serotype-specific outbreak of group B meningococcal disease in Iquique, Chile. Epidemiology and Infection 1990; 105: 119-126.

15. Puricelli RC, Kupek E, Westrupp MH. Three decades of meningococcal disease in the State of Santa Catarina, Brazil. Brazilian Journal of Infectious Diseases 2004; 8: 241-248.

16. Dominguez F, Menendez J, Ochoa R. An effective serogroup B meningococcal vaccine. Vaccine 2006; 24 : 7025-7026. 
17. de Moraes JC, et al. Protective efficacy of a serogroup B meningococcal vaccine in Sao Paulo, Brazil. Lancet 1992; 340: 1074-1078.

18. Noronha CP, Struchiner J, Halloran ME. Assessment of the direct effectiveness of $\mathrm{BC}$ meningococcal vaccine in Rio de Janeiro, Brazil: A case-control study. International Journal of Epidemiology 1995; 24: 10501057.

19. Pirez MC, et al. Control of an outbreak of serogroup B meningococcal disease. Revista Medica del Uruguay 2004; 20: 92-101.

20. Jodar L, et al. Development of vaccines against meningococcal disease. Lancet 2002; 359: 1499-1508.

21. Safadi MAP, Cintra OAL. Epidemiology of meningococcal disease in Latin America: Current situation and opportunities for prevention. Neurological Research 2010; 32: 263-271.

22. Halperin SA, et al. The changing and dynamic epidemiology of meningococcal disease. Vaccine 2012; 30(Suppl. 2): B26-B36.

23. Almeida-Gonzalez L, et al. Meningococcal disease: epidemiological, clinical and preventive perspectives. Salud Publica de México 2004; 46: 438-450.

24. Barata RC. Epidemiology of meningococcal disease, 1970/1977. Onset and dissemination of the epidemic process. Revista de Saude Publica 1988; 22: 16-24.

25. de Moraes JC, Barata RB. Meningococcal disease in Sao Paulo, Brazil, in the 20th century: epidemiological characteristics. Cadernos de Saude Publica 2005; 21: 1458-1471.

26. Division of General Epidemiology. Annual morbiditytextbook 1984-2010 (http://www.dgepi.salud.gob.mx/ anuario/html/anuarios.html). Accessed 25 July 2012.

27. Chacon-Cruz E, et al. Surveillance for invasive meningococcal disease in children, US-Mexico border, 2005-2008. Emerging Infectious Diseases 2011; 17: 543-546.

28. Pan American Health Organization. Regional system for vaccines SIREVA II: data by country and age groups on characterization of Streptococcus pneumoniae, Haemophilus influenzae and Neisseria meningitidis isolates from invasive diseases, 2000-2005.

29. Pan American Health Organization. Meningococcal disease outbreak in Osorno, Chile. Epidemiological Bulletin 1980; 1: 9-10.

30. Caugant DA, Froholm LO, Bovre K. Intercontinental spread of a genetically distinctivecomplex of clones of Neisseria meningitidis causing epidemic disease. Proceedings of the National Academy of Sciences 1986; 83 : 4927-4931.

31. Motas IM, et al. Characterization of Neisseria meningitidis strains isolated from carriers in Cuba during 20 years. Revista Cubana de Medicina Tropical 2006; 58: 124-133.

32. Sosa $\mathbf{J}$, et $\boldsymbol{a l}$. Typing and susceptibility to penicillin of Neisseria meningitidis isolated from patients in Cuba (1993-1999). Memorias do Instituto Oswaldo Cruz 2001; 96: $523-525$.

33. Sacchi CT, et al. Ongoing group B Neisseria meningitidis epidemic in Sao Paulo, Brazil, due to increased prevalence of a single clone of the ET-5 complex. Journal of Clinical Microbiology 1992; 30: 1734-1738.

34. Barroso DE, et al. The effect of subcapsular meningococcal $\mathrm{B}+\mathrm{C}$ vaccine on the prognosis of patients with meningococcal disease. Scandinavian Journal of Infectious Diseases 2002; 34: 417-420.

35. Lemos AP, et al. Phenotypic characterization of Neisseria meningitidis strains isolated from invasive disease in Brazil from 1990 to 2001. Journal of Medical Microbiology 2006; 55: 751-757.

36. Rodriguez AP, et al. The epidemiological impact of antimeningococcal $\mathrm{B}$ vaccination in Cuba. Memórias do Instituto Oswaldo Cruz 1999; 94: 433-440.

37. Milagres LG, et al. Immune response of Brazilian children to a Neisseria meningitidis serogroup B outer membrane protein vaccine: Comparison with efficacy. Infection and Immunity 1994; 62: 4419-4424.

38. Galeano A, Echeverry ML. Effectiveness of a meningococcal vaccine in Itagui, Colombia. Boletim Epidemiológico de Antioquia 1995; 2: 20.

39. Agudelo CI, Sanabria OM, Ovalle MV. Serogroup Y meningococcal disease, Colombia. Emerging Infectious Diseases 2008; 14: 990-991.

40. Castillo L, et al. Characteriztion of Neisseria meningitidis strains isolated from invasive infections. Chile, 1992-1993. Revista Médica de Chile 1994; 122: 760 767.

41. Pirez MC, et al. Invasive meningococcal disease in Uruguay. Revista Médica del Uruguay 2002; 18: 83-88.

42. Pan American Health Organization. Regional system for vaccines SIREVA II: data by country and age groups on characterization of Streptococcus pneumoniae, Haemophilus influenzae and Neisseria meningitidis isolates from invasive diseases, 2006. 2006.

43. Pan American Health Organization. Regional system for vaccines SIREVA II: data by country and age groups on characterization of Streptococcus pneumoniae, Haemophilus influenzae and Neisseria meningitidis isolates from invasive diseases, 2007. 2007.

44. Pan American Health Organization. Regional system for vaccines SIREVA II: data by country and age groups on characterization of Streptococcus pneumoniae, Haemophilus influenzae and Neisseria meningitidis isolates from invasive diseases, 2008. 2008.

45. Feldman RA, et al. Meningococcal meningitis in Costa Rica, 1970-1973. Boletín médico del Hospital Infantil de México 1979; 36: 279-286.

46. de Morais $\mathbf{J}$, et al . Epidemic disease due to serogroup C Neisseria meningitidis in Sao Paulo, Brazil. Journal of Infectious Diseases 1974; 129: 568-571.

47. Sacchi CT, et al. Characterization of epidemic Neisseria meningitidis serogroup C strains in several Brazilian states. Journal of Clinical Microbiology 1994; 32: 1783-1787.

48. Lemos APS, et al. Clonal distribution of invasive Neisseria meningitidis serogroup C strains circulating from 1976 to 2005 in greater Sao Paulo, Brazil. Journal of Clinical Microbiology 2007; 45: 1266-1273.

49. Barroso D, et al. Epidemiology and molecular analysis of epidemic meningococcal disease related to group $\mathrm{C}$ 
Neisseria meningitidis in a Brazilian metropolis. 1996. Tenth International Pathogenic Neisseria Conference, Baltimore, Maryland, 8-13 September 1996, Abstract 150 (http://neisseria.org/ipnc/1996/Neis 1996-chap7.pdf). Accessed 3 March 2011.

50. Ministry of Health. Meningococcal disease in Brazil. 2011 (http://portal.saude.gov.br/portal/saude/ profissional/visualizar_texto.cfm?idtxt $=37810)$. Accessed 2 March 2011.

51. Chiavetta L, et al. Neisseria meningitidis surveillance in Argentina, 1993-2005: distribution of serogroups, serotypes and serosubtypes causing invasive disease. Revista Argentina de Microbiologia 2007; 39: 21-27.

52. Ministry of Health, Chile. Meningococcal disease (MD) epidemiology in Chile, 2011 (http://epi.minsal.cl/epi/ html/bolets/reportes/meningitis/meningitis.pdf). Accessed 2 March 2011.

53. Pan American Health Organization. Regional system for vaccines SIREVA II: data by country and age groups on characterization of Streptococcus pneumoniae, Haemophilus influenzae and Neisseria meningitidis isolates from invasive diseases, 2009. 2009.

54. Barroso DE, Rebelo MC. Recognition of the epidemiological significance of Neisseria meningitidis capsular serogroup W135 in the Rio de Janeiro region, Brazil. Memórias do Instituto Oswaldo Cruz 2007; 102: 773-775.

55. Weidlich L, et al. High prevalence of Neisseria meningitidis hypervirulent lineages and emergence of W135:P1.5,2:ST-11 clone in Southern Brazil. Journal of Infection 2008; 57: 324-331.

56. von Gottberg A, et al. Emergence of endemic serogroup W135 meningococcal disease associated with a high mortality rate in South Africa. Clinical Infectious Diseases 2008; 46: 377-386.

57. Abad R, et al. Molecular characterization of invasive serogroup Y Neisseria meningitidis strains isolated in the Latin America region. Journal of Infection 2009; 59: 104-114.

58. Ministry of Health, Chile. Meningococcal disease (MD) epidemiology in Chile, 2010 (http://epi.minsal.cl/ epi/html/bolets/reportes/Meningitis/meningitisold 1 . pdf).

59. Argentine Society of Pediatrics. National vaccine consensus, 2011 (http://www.sap.org.ar/docs/publicaciones/ ConsensoVacunas2011.pdf). Accessed 2 March 2011.

60. Nieto-Guevara J, et al. Epidemiology of meningococcal disease in the Panamanian pediatric population, 1998-2008. Journal of Infection in Developing Countries 2011; 5: 318-323.

61. Pan American Health Organization. Current situation of meningococcal disease surveillance in the Americas region. Washington, DC; 2007. Report No.: CDCPAHO/Dpc/Cd/A/482.

62. Ministry of Health, Brazil. Outbreak of serogroup C meningococcal disease in Porto Seguro/Bahia, 2009 (http://www2.saude.ba.gov.br/divep/arquivos/Boletins \% 20Epidemiologicos/Meningite/2009/Nota\%20Meningite $\%$ 20em \%20Porto \%20Seguro \%20(04-11-2009).pdf). Accessed 25 July 2012.
63. Castellano Gonzalez M. Nasopharyngeal carriage of potentially pathogenic bacteria in toddlers from Maracaibo (2000-2001). Kasmera 2002; 30: 17-32.

64. de los Monteros LE, et al. Prevalence of Neisseria meningitidis carriers in children under five years of age and teenagers in certain populations of Mexico City. Salud Pública de México 2009; 51: 114-118.

65. Soriano-Gabarro M, et al. Carriage of Neisseria meningitidis in Europe: a review of studies undertaken in the region. Expert Review of Anti-infective Therapy $2011 ; 9:$ 761-774.

66. Christensen $\mathbf{H}$, et al. Meningococcal carriage by age: a systematic review and metaanalysis. Lancet Infectious Diseases 2010; 10: 853-861.

67. Franco-Paredes C, et al. Epidemiology and outcomes of bacterial meningitis in Mexican children: 10-year experience (1993-2003). International Journal of Infectious Diseases 2008; 12: 380-386.

68. Almeida-Gonzalez L, et al. Meningococcal disease: epidemiological, clinical, and preventive perspectives. Salud Publica de México 2004; 46: 438-450.

69. Dickinson FO, Perez AE. Bacterial meningitis in children and adolescents: an observational study based on the national surveillance system. BMC Infectious Diseases 2005; 5: 103.

70. Ministry of Health, Panama. Meningococcal Disease situation, 1990-2008, 2009 (http://www.minsa.gob.pa/ minsa/tl_files/documents/informacion_salud/meningo cocica/meningoccica.pdf). Accessed 2 March 2011.

71. Santos ML, Ruffino-Netto A. Meningococcal disease: epidemiological profile in the Municipality of Manaus, Amazonas, Brazil, 1998/2002. Cadernos de Saude Publica 2005; 21 : 823-829.

72. Cordeiro SM, et al. Hospital-based surveillance of meningococcal meningitis in Salvador, Brazil. Transactions of the Royal Society of Tropical Medicine and Hygiene 2007; 101: 1147-1153.

73. Baethgen LF, et al. Epidemiology of meningococcal disease in southern Brazil from 1995 to 2003, and molecular characterization of Neisseria meningitidis using multilocus sequence typing. Tropical Medicine \& International Health 2008; 13: 31-40.

74. Costa EDA, Martins H, Klein CH. Evaluation of the protective efficacy of an antimeningococcal vaccine for serogroups B and C Neisseria meningitidis infections in Brazil, 1990/92. Revista de Saude Publica 1996; 30: 460-470.

75. Bastos CO, et al. Meningitis. Considerations on 15067 cases confined at the 'Emilio Ribas' Hospital during the 1958-1972 period. Revista da Associação Medica Brasileira 1973; 19: 451-456.

76. Donalisio MR, et al. Fatality rate in the epidemiology of meningococcal disease: study in the region of Campinas, SP, Brazil, 1993 to 1998. Revista de Saude Publica 2000; 34: 589-595.

77. Gama SG, Marzochi KB, da Siveira Filho GB. Epidemiological characterization of meningococcal disease in a metropolitan area in Southeastern Brazil, 1976-1994. Revista de Saude Publica 1997; 31 : 254-262. 
78. Espinal CA, Espinosa G, Upegui G. Epidemiology of meningococcal Disease in Colombia. Infectio 1999; 3: 74-87.

79. Pereira CS, Reguera M, Mollerach M. PorA types in Neisseria meningitidis serogroup B isolated in Argentina from 2001 to 2003: implications for the design of an outer membraneprotein-based vaccine. Journal of Medical Microbiology 2008; 57: 338-342.
80. Argentine Society of Pediatrics. National committee of infectious diseases, Meningoencephalitis, 2008 (http:// www.sap.org.ar/staticfiles/comunicaciones/menin 2008 . pdf). Accessed 2 March 2011.

81. Tappero JW, et al. Immunogenicity of 2 serogroup B outer-membrane protein meningococcal vaccines: A randomized controlled trial in Chile. Journal of the American Medical Association 1999; 281 : 1520-1527. 